\title{
Climate trends and behaviour of drought indices based on precipitation and evapotranspiration in Portugal
}

\author{
A. A. Paulo ${ }^{1,2}$, R. D. Rosa ${ }^{1}$, and L. S. Pereira ${ }^{1}$ \\ ${ }^{1}$ CEER-Biosystems Engineering, Institute of Agronomy, Technical University of Lisbon, Portugal \\ ${ }^{2}$ Escola Superior Agrária de Santarém, Portugal \\ Correspondence to: L. S. Pereira (lspereira@isa.utl.pt)
}

Received: 4 January 2012 - Revised: 19 March 2012 - Accepted: 20 March 2012 - Published: 16 May 2012

\begin{abstract}
Distinction between drought and aridity is crucial to understand water scarcity processes. Drought indices are used for drought identification and drought severity characterisation. The Standardised Precipitation Index (SPI) and the Palmer Drought Severity Index (PDSI) are the most known drought indices. In this study, they are compared with the modified PDSI for Mediterranean conditions (MedPDSI) and the Standardised Precipitation Evapotranspiration Index (SPEI). MedPDSI results from the soil water balance of an olive crop, thus real evapotranspiration is considered, while SPEI uses potential (climatic) evapotranspiration. Similarly to the SPI, SPEI can be computed at various time scales. Aiming at understanding possible impacts of climate change, prior to compare the drought indices, a trend analysis relative to precipitation and temperature in 27 weather stations of Portugal was performed for the period 1941 to 2006. A trend for temperature increase was observed for some weather stations and trends for decreasing precipitation in March and increasing in October were also observed for some locations. Comparisons of the SPI and SPEI at 9- and 12-month time scales, the PDSI and MedPDSI were performed for the same stations and period. SPI and SPEI produce similar results for the same time scales concerning drought occurrence and severity. PDSI and MedPDSI correlate well between them and the same happened for SPI and SPEI. PDSI and MedPDSI identify more severe droughts than SPI or SPEI and identify drought occurrence earlier than these indices. This behaviour is likely to be related with the fact that a water balance is performed with PDSI and MedPDSI, which better approaches the supplydemand balance.
\end{abstract}

\section{Introduction}

Drought is a natural feature of climate and occurs in almost all climatic regions with varying frequency, severity and duration (Wilhite, 1993). It can be defined as a temporary imbalance of water availability consisting of a persistent lower than average precipitation of uncertain frequency, duration and severity, of unpredictable or extremely hard to predict occurrence, resulting in diminished water resources availability (Pereira et al., 2009). Drought is both a hazard and a disaster; a hazard because it is an accident of unpredictable occurrence, part of the naturally variable climate system; disaster because it corresponds to the failure of the precipitation regime, causing the disruption of the water supply to the natural and agricultural ecosystems as well as to other human activities. Drought definitions are many and often are related with specific drought impacts on economic activities, ecosystems, and society and water management issues (Dracup et al., 1980; Yevjevich et al., 1983; Wilhite and Glantz, 1987; Tate and Gustard, 2000). Differences in perception is a main problem of water management for drought (Grigg and Vlachos, 1990). There is a delay between precipitation failure and both the perception of drought and drought effects, shorter for crops and vegetation at their critical growth periods and longer for subsurface reservoirs. The drought onset is slow and difficult to perceive as a true drought initiation. Often, drought ending is also slow and drought effects persist after the causes have vanished. High temperatures and high evapotranspiration rates can aggravate drought effects.

Unlike drought, aridity is a permanent climatic feature corresponding to an imbalance in water availability consisting in low average annual rainfall, with high spatial and temporal variability resulting in overall low moisture and low carrying capacity of the ecosystems (Pereira et al., 2009). Aridity may be expressed through climatological indices, 
often defined through a precipitation/evapotranspiration ratio (Arora, 2002; UNEP, 1992). The long-term average of the aridity indices computed on a yearly basis quantifies the degree of climatic dryness of a region. However, those ratios can be computed on a monthly basis to define a drought index, e.g. the RDI (Tsakiris et al., 2007). Vicente-Serrano et al. (2010b) used precipitation minus potential evapotranspiration (P-ET) to assess yearly changes in the degree of aridity, which they referred as aridification.

Drought indices evaluate the departure of climate variables in a given time interval (month, season or year) from the "normal" conditions and are used as monitoring tools and operational indicators for water managers. Several drought indices have been developed, most of them based only on precipitation, some based on precipitation and evapotranspiration (ET), and others referring to runoff and vegetation conditions (Heim, 2002). Keyantash and Dracup (2002) evaluated the performance and tractability of the most used drought indices, whereas Mishra and Singh (2010) reviewed drought concepts and compared drought indices.

The Palmer Drought Severity Index, PDSI (Palmer, 1965) and the Standardized Precipitation Index, SPI (McKee et al., 1993, 1995), are widely used in drought monitoring and have been tested worldwide. The Standardised Precipitation Evapotranspiration Index (SPEI) includes precipitation and potential evapotranspiration (PET) in its formulation; it may express the water supply-demand relation and may accommodate climate change influences (Vicente-Serrano et al., 2010a). Differently, the MedPDSI, which is a modification of the PDSI for Mediterranean conditions, was developed to adopt an updated formulation of the water balance and to consider real evapotranspiration instead of PET, thus approaching better the behaviour of natural and man-made ecosystems in terms of water supply-demand (Pereira et al., 2007; Pereira and Rosa, 2010).

This study aims at assessing the behaviour of the SPI, SPEI, PDSI and MedPDSI indices throughout Portugal and comparing them using data from several weather stations located in regions with different aridity. Moreover, to better understanding results, precipitation and temperature trends in Portugal in the period 1941-2006 were investigated.

\section{Material and methods}

\subsection{Data}

This study was applied in Portugal, using monthly records of precipitation and maximum and minimum air temperature from 27 weather stations belonging to the state meteorological agency, IM, concerning the common period 1941-2006 (Fig. 1).

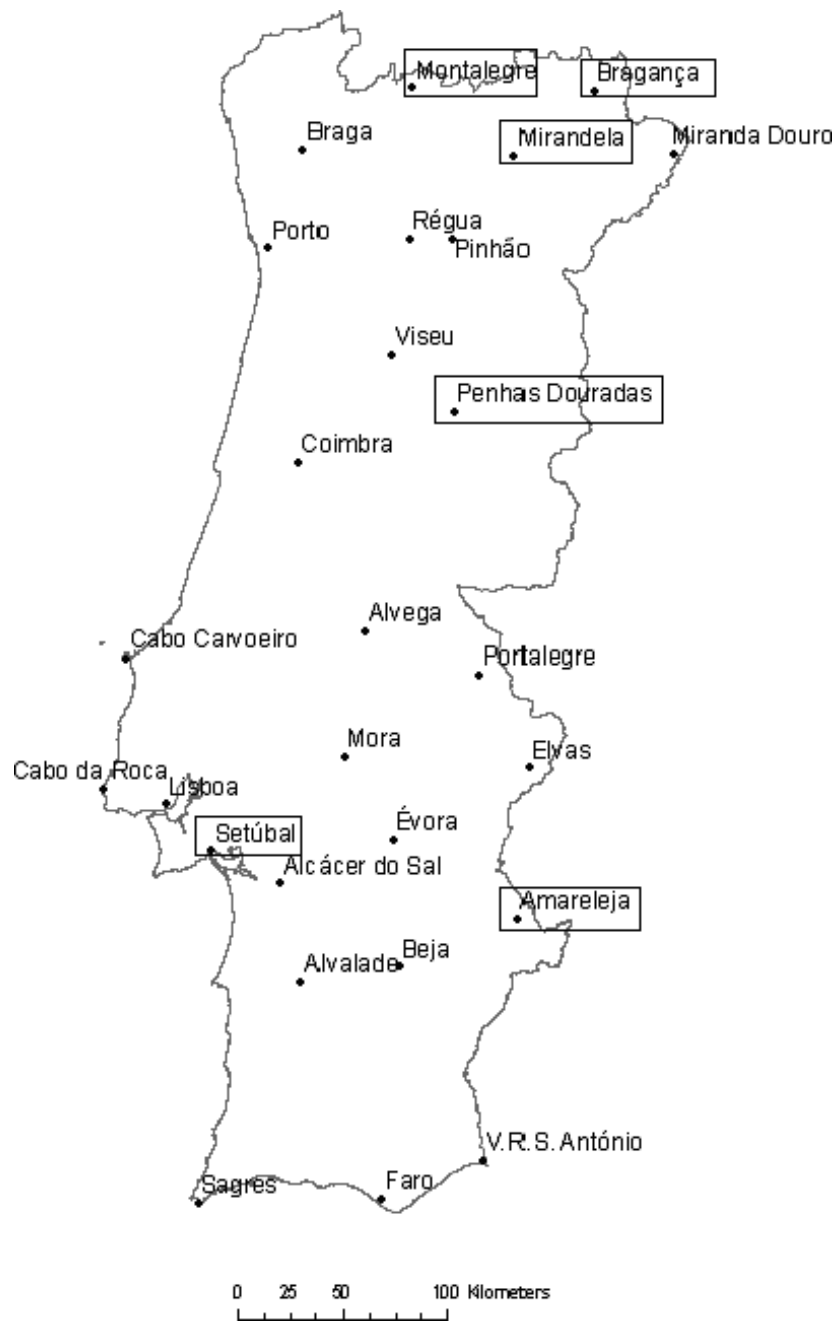

Fig. 1. Locations of the weather stations with identification of those used as examples in this paper.

The quality of annual precipitation records was investigated through non-parametric tests. Randomness, homogeneity and absence of trends were tested using the Kendall autocorrelation test, the Mann-Kendall trend test, and the homogeneity tests of Mann-Whitney for mean and variance (Helsel and Hirsch, 1992). When the hypothesis of homogeneity fails (significance level 0.05 ), each month of the series was corrected by the method of cumulative residuals (described by Allen et al., 1998) using as reference nearby homogeneous data sets and considering a confidence level of $80 \%$ (Rosa et al., 2010b). The missing data for either precipitation or the maximum and minimum temperature were estimated from nearby stations using either linear regression or MOVE linear models (Hirsch, 1982; Vogel and Stedinger, 1985; Helsel and Hirsch, 1992), which preserved the variance and order statistics of the completed series when more than $5 \%$ values were missing (Rosa et al., 2010b). 
Table 1. Coordinates and altitude of the weather stations used in this study, respective aridity index and precipitation and temperature trends.

\begin{tabular}{|c|c|c|c|c|c|c|c|c|c|}
\hline \multirow[t]{2}{*}{ Stations } & \multirow[t]{2}{*}{ Latitude } & \multirow[t]{2}{*}{ Longitude } & \multirow[t]{2}{*}{ Altitude } & \multirow{2}{*}{$\begin{array}{r}\text { Aridity } \\
\text { Index }\end{array}$} & \multicolumn{2}{|c|}{$\begin{array}{l}\text { Precipitation trend } \\
\quad\left(\mathrm{mm} \mathrm{yr}^{-1}\right)\end{array}$} & \multicolumn{3}{|c|}{$\begin{array}{l}\text { Mean temperature trend } \\
\qquad\left({ }^{\circ} \mathrm{C} \mathrm{yr}^{-1}\right)\end{array}$} \\
\hline & & & & & Mar & Oct & Aug & Dec & Year \\
\hline Alcacer do Sal & 38.38 & -8.52 & 51 & 0.409 & -0.883 & 0.885 & 0.025 & & 0.015 \\
\hline Alvalade & 37.95 & -8.40 & 61 & 0.377 & -0.700 & & & & \\
\hline Alvega & 39.47 & -8.05 & 51 & 0.484 & -1.114 & 1.160 & & & \\
\hline Amareleja & 38.22 & -7.22 & 192 & 0.347 & -0.746 & 0.581 & 0.013 & 0.029 & 0.020 \\
\hline Beja & 38.02 & -7.87 & 246 & 0.415 & -1.009 & 0.552 & 0.018 & 0.018 & 0.012 \\
\hline Braga & 41.55 & -8.40 & 190 & 1.286 & -1.518 & 1.577 & 0.023 & 0.016 & \\
\hline Bragança & 41.80 & -6.73 & 691 & 0.637 & -0.742 & 0.693 & 0.026 & 0.019 & 0.016 \\
\hline Cabo Carvoeiro & 39.35 & -9.40 & 32 & 0.856 & -0.597 & 0.840 & 0.018 & 0.015 & 0.010 \\
\hline Cabo da Roca & 38.78 & -9.50 & 142 & 0.700 & & 0.870 & 0.033 & 0.021 & 0.019 \\
\hline Coimbra/Bencanta & 40.20 & -8.42 & 107 & 0.715 & -0.900 & 1.135 & 0.022 & & 0.015 \\
\hline Elvas & 38.88 & -7.15 & 208 & 0.391 & -1.005 & & 0.020 & 0.025 & 0.017 \\
\hline Evora & 38.57 & -7.90 & 309 & 0.543 & -1.277 & & 0.020 & & 0.011 \\
\hline Faro Aeroporto & 37.02 & -7.97 & 7 & 0.450 & -0.789 & & & & 0.011 \\
\hline Lisboa (Geofisico) & 38.72 & -9.15 & 77 & 0.696 & -0.998 & 0.912 & 0.016 & & 0.012 \\
\hline Miranda do Douro & 41.52 & -6.28 & 693 & 0.494 & -0.548 & 0.900 & & 0.024 & 0.010 \\
\hline Mirandela & 41.52 & -7.20 & 250 & 0.364 & -0.500 & 0.700 & & & \\
\hline Montalegre & 41.82 & -7.78 & 1005 & 1.547 & -1.406 & 2.088 & 0.030 & 0.028 & 0.021 \\
\hline Mora & 38.93 & -8.17 & 110 & 0.435 & -1.012 & & & & 0.012 \\
\hline Penhas Douradas & 40.42 & -7.55 & 1380 & 2.080 & -2.150 & 1.464 & & & 0.015 \\
\hline Pinhao (Santa Barbara) & 41.17 & -7.55 & 130 & 0.453 & -0.756 & 0.846 & & & \\
\hline Portalegre & 39.28 & -7.42 & 597 & 0.797 & -1.293 & & & & \\
\hline Porto-Serra do Pilar & 41.13 & -8.60 & 93 & 1.206 & -1.070 & 1.343 & 0.025 & 0.022 & 0.014 \\
\hline Regua & 41.17 & -7.80 & 65 & 0.660 & -1.251 & & 0.039 & 0.026 & 0.025 \\
\hline Sagres & 37.00 & -8.95 & 25 & 0.547 & & & 0.043 & & 0.014 \\
\hline Setubal & 38.52 & -8.90 & 35 & 0.571 & -1.100 & 1.014 & 0.025 & & 0.014 \\
\hline Vila Real de S. Antonio & 37.18 & -7.42 & 7 & 0.389 & -0.597 & & & 0.019 & 0.011 \\
\hline Viseu & 40.67 & -7.90 & 443 & 0.886 & -1.450 & & 0.033 & 0.025 & 0.022 \\
\hline
\end{tabular}

\subsection{Methods}

Trends in monthly, seasonal and annual precipitation and mean air temperature were investigated through the MannKendall original and modified trend test (Hamed and Rao, 1998), which accounts for temporal autocorrelation and has already been applied in drought indices trend detection (Sousa et al., 2011). A significance level of 0.05 was adopted. When significant, the magnitude of the existing trend was estimated with the Sen slope estimator (Sen, 1968; Helsel and Hirsch, 1992; Huth and Pokorná, 2004).

Various aridity indices were developed, mainly relating potential evapotranspiration (PET) and precipitation (P). Using the UNEP index (UNEP, 1992), regions were classified from hyper-arid to humid; however different classification limits may be used according to the selected PET equation, which refers to specific objectives of aridity quantification (Arora, 2002). The UNEP aridity index, given by the average of annual P/PET ratio over several years, was computed for the 27 weather stations in the period 1941-2006 (Table 1). PET was estimated from the Penman-Monteith ref- erence ET computed with the temperature approach (Allen et al., 1998). The locations were then classified as semi-arid $(0.2<\mathrm{P} / \mathrm{PET}<=0.5)$, sub-humid $(0.5<\mathrm{P} / \mathrm{PET}<=0.75)$ or humid (P/PET $>0.75)$.

In this study, the drought indices SPI, SPEI, PDSI, and MedPDSI are compared. The SPI is based on the probability distribution of the precipitation, usually the two-parameter gamma distribution (McKee et al., 1993). It only needs precipitation as input data, can be computed in multiple time scales, and is a normalised index allowing comparability over time and space. The SPI has been applied successfully in Portugal for drought identification (Paulo and Pereira, 2006) and prediction of drought class transitions (Paulo and Pereira, 2008; Moreira et al., 2008).

The SPEI is based on the probability distribution of the difference P-PET cumulated over different time scales and is normalised following the SPI drought classification (VicenteSerrano et al., 2010a). The authors chose the L-moment parameter estimation and the log-logistic distribution as the one that best fits cumulated P-ET for 3 to 18 month time scales. Its possible sensitivity to climate change was the 

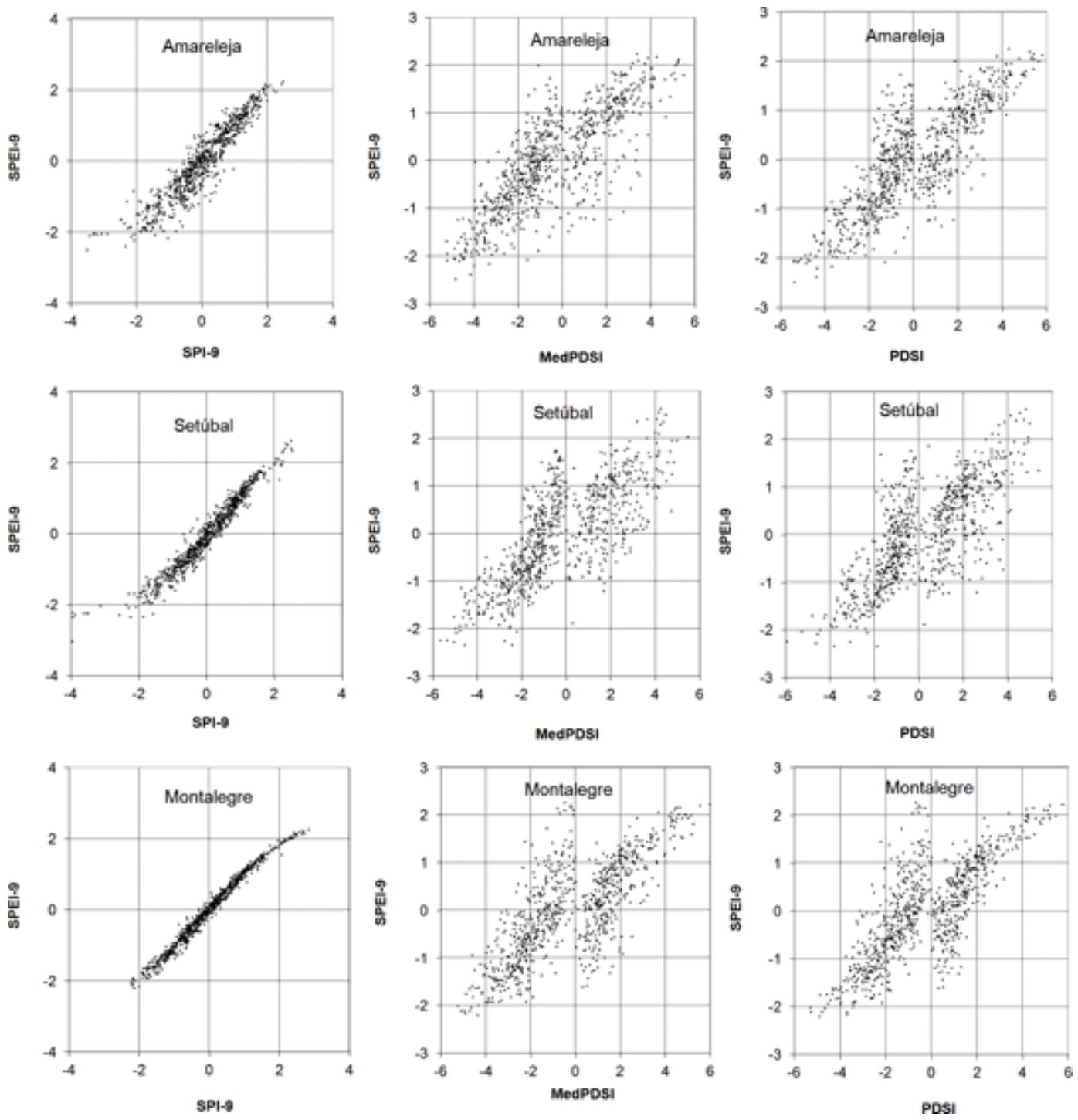

Fig. 2. Scatterplots of SPI-9, MEDPDSI and PDSI vs. SPEI-9month in Amareleja, Setúbal and Montalegre computed for the period 19412006.

reason for its consideration in this study. The difference $\mathrm{P}-$ PET is referred to as a climatic water balance, where monthly PET was computed with the Thornthwaite equation (Thornthwaite, 1948).

The PDSI (Palmer, 1965) is based on the supply-anddemand concept of the soil water balance applied to a twolayer soil model using monthly precipitation and PET data. The index bases upon the calculation of the moisture departure between actual precipitation and the precipitation expected to occur for the average conditions of the climate, which implies performing a monthly water balance and the calibration of local monthly coefficients for the various terms of the soil water balance. In addition, the calibration of the index is required at local or regional level. The PDSI values depend upon the available soil water capacity (AWC) of the underlying layer, on the PET method when different of the original Thornthwaite equation, and on the calibration procedures adopted (Alley, 1984; Karl, 1986). Good results have been obtained with the method worldwide. However, the method has limitations as pointed out by several authors (e.g. Alley, 1984; Guttman, 1997; Heddingaus and Sabol, 1991). The limitations relate to the soil water balance procedure, the impacts of selecting a given PET equation, the empirical equation used to obtain the moisture anomaly index, the empirical coefficients of the recursive equations relating the moisture anomaly index with the three intermediate indices that express the severity of a wet/dry category, and the backtracking procedure to choose the actual PDSI from one of the three indices. 
Table 2. Pearson correlation coefficient between monthly values of drought indices in selected stations representing different climates (1941-2006).

\begin{tabular}{|c|c|c|c|c|c|c|c|}
\hline \multirow{2}{*}{$\begin{array}{l}\text { Climatic region and } \\
\text { location }\end{array}$} & & \multicolumn{2}{|c|}{ Semi-arid } & \multicolumn{2}{|c|}{ Sub-humid } & \multicolumn{2}{|c|}{ Humid } \\
\hline & & Amareleja & Mirandela & Setubal & Bragança & Montalegre & Penhas Douradas \\
\hline Aridity index & & 0.347 & 0.364 & 0.571 & 0.637 & 1.547 & 2.080 \\
\hline \multirow[t]{5}{*}{ MedPDSI } & PDSI & 0.876 & 0.929 & 0.813 & 0.938 & 0.941 & 0.960 \\
\hline & SPEI-9 & 0.801 & 0.831 & 0.765 & 0.777 & 0.747 & 0.732 \\
\hline & SPEI-12 & 0.792 & 0.801 & 0.734 & 0.729 & 0.689 & 0.684 \\
\hline & SPI-9 & 0.809 & 0.838 & 0.763 & 0.759 & 0.741 & 0.733 \\
\hline & SPI-12 & 0.799 & 0.803 & 0.733 & 0.708 & 0.679 & 0.683 \\
\hline \multirow[t]{4}{*}{ PDSI } & SPEI-9 & 0.825 & 0.851 & 0.757 & 0.802 & 0.763 & 0.751 \\
\hline & SPEI-12 & 0.823 & 0.840 & 0.741 & 0.758 & 0.698 & 0.695 \\
\hline & SPI-9 & 0.793 & 0.821 & 0.759 & 0.779 & 0.752 & 0.750 \\
\hline & SPI-12 & 0.791 & 0.810 & 0.741 & 0.733 & 0.685 & 0.692 \\
\hline SPI-12 & SPEI-12 & 0.941 & 0.953 & 0.970 & 0.980 & 0.991 & 0.995 \\
\hline SPI-9 & SPEI-9 & 0.931 & 0.949 & 0.966 & 0.978 & 0.990 & 0.994 \\
\hline
\end{tabular}

To overcome some of these limitations and to improve adherence of the index to regional conditions, the original method was modified to develop a new index well adapted to Mediterranean conditions, the MedPDSI (Pereira et al., 2007). The soil water balance is performed with the model ISAREG (Liu et al., 1998), thus replacing the former twolayer computation by a soil that represents an agricultural soil cropped with a rainfed olive orchard. The reference ET $\left(\mathrm{ET}_{\mathrm{o}}\right)$ defined by the FAO Penman-Monteith equation is used and is computed from the maximum and minimum temperature (Allen et al., 1998). Non-stressed crop ET $\left(\mathrm{ET}_{\mathrm{m}}\right)$ is computed with an appropriate crop coefficient $\left(K_{\mathrm{c}}\right)$ as $\mathrm{ET}_{\mathrm{m}}=K_{\mathrm{c}}$ $\mathrm{ET}_{\mathrm{o}}$. The value of $K_{\mathrm{c}}$ is that for rainfed olives and varies for each month and with the available soil water and rainfall (Pereira et al., 2007; Pereira and Rosa, 2010a). The soil water balance model computes the real evapotranspiration, $\mathrm{ET}_{\mathrm{a}}$ as follows: $\mathrm{ET}_{\mathrm{a}}=\mathrm{ET}_{\mathrm{m}}$ in non-stress conditions, i.e. when the soil water is above a non-stress threshold; $\mathrm{ET}_{\mathrm{a}}<\mathrm{ET}_{\mathrm{m}}$ and $\mathrm{ET}_{\mathrm{a}}$ decreases as the soil loses water when the soil water content is below the non-stress threshold (Pereira et al., 2007). The procedures used for computation of the indices follow those described by Alley (1984) and Karl (1986) as analyzed by Rosa et al. (2010a). The calibration for both PDSI and MedPDSI consisted in the computation of the climatic characteristic and the empirical coefficients of the recursive equations relating the moisture anomaly index with the final drought index. The climatic characteristic was estimated following Ntale and Gan (2003). The recursive equations were calibrated locally for both humid and dry conditions (Rosa et al., 2010b).

The comparison of pairs of drought indices used graphic approaches and descriptive statistics such as an intercomparison of indices relative to each location using the Pearson correlation coefficient (Chambers et al., 1983; Draper and Smith, 1998).

\section{Results}

\subsection{Trend analysis for precipitation and temperature}

To better understand the behaviour of the SPI, SPEI, PDSI, and MedPDSI indices throughout Portugal, and sprecifically to verify if drought indices using PET instead of real ET could be adequate to foresee impacts of climate change, a trend analysis for monthly precipitation and temperature was performed for all weather stations in the period 1941-2006. In addition, an aridity index was calculated for all stations and the same period. The most relevant trends for precipitation and mean temperature, along with the the aridity index, are presented in Table 1; the coordinates and altitude of the weather stations are also given there. Results for precipitation are contrasting, with decreases in March and increases in October. No annual trends were found and seasonal trends were not evident. The decreasing trend in March is statistically significant in 25 out of the 27 stations analysed, with a median value of $-1.0 \mathrm{~mm} \mathrm{yr}^{-1}$. The larger negative trends were observed for northern humid locations; the largest $\left(-2.2 \mathrm{~mm} \mathrm{yr}^{-1}\right)$ was identified for Penhas Douradas, the station with highest altitude, $1380 \mathrm{~m}$. In October, a significant positive trend was identified in 17 out of 27 stations, ranging 0.6 to $2.1 \mathrm{~mm} \mathrm{yr}^{-1}$, with highest values for northern locations. The larger trend was observed for Montalegre $\left(2.1 \mathrm{~mm} \mathrm{yr}^{-1}\right)$, in a mountainous area of the North. These findings are in agreement with former studies, e.g. de Lima et al. (2010) and Sousa et al. (2011).

For the mean annual temperature, a positive significant trend was detected in 21 out of 27 stations, with a median value of $0.014^{\circ} \mathrm{C} \mathrm{yr}^{-1}$. No spatial trends were observed. The highest increase was observed for Régua, located in the dry region of Port wine production. The months with highest increases are August and December, while the lowest were 

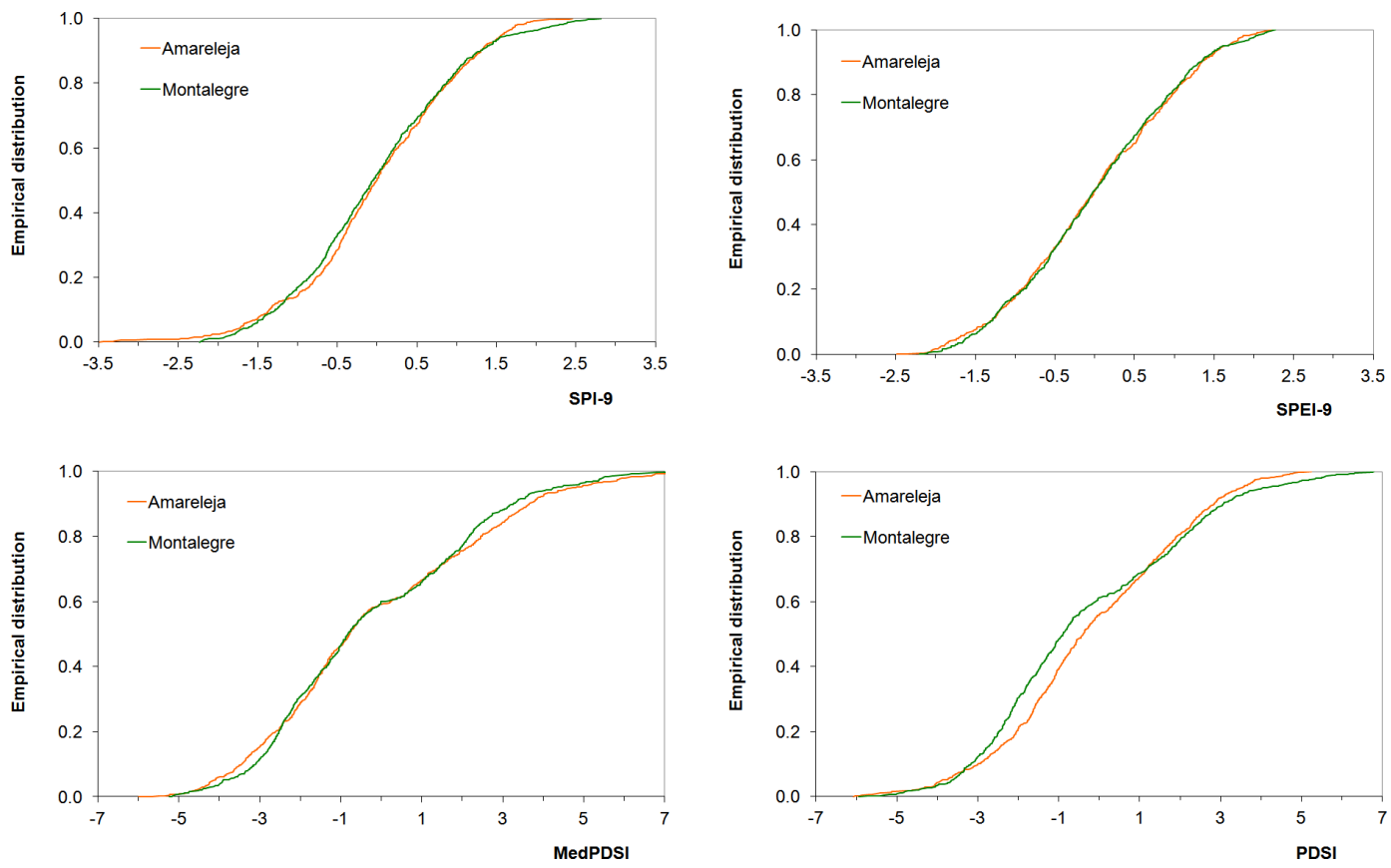

Fig. 3. Empirical distributions of SPI-9, SPEI-9, MedPDSI and PDSI in Amareleja (semi-arid) and Montalegre (humid) computed for the period 1941-2006.

observed for the spring and autumn months. In August a positive significant trend was found in 17 out of 27 stations, with a median value of $0.025^{\circ} \mathrm{Cyr}^{-1}$.

The aridity index varies from 0.347 at Amareleja up to 2.080 at Penhas Douradas, thus revealing that a locations' climate varies from semi-arid to humid. Most locations have a sub-humid climate. No significant relations were found between the aridity index and the climate trends observed. For better developing the analysis of drought indices' behaviour, the stations selected for presentation in this paper refer to Amareleja and Mirandela (semi-arid), Setubal and Bragança (sub-humid), and Montalegre and Penhas Douradas (humid), as shown in Fig. 1.

\subsection{Drought indices comparison}

As expected, the MedPDSI and the PDSI are highly correlated (Table 2). The correlation between SPI and SPEI in a given time scale is also high. When considering the relation between MedPDSI or PDSI and SPI or SPEI, there is a better correlation for the 9-month rather than for the 12-month time scale. The correlation coefficients between PDSI(MedPDSI) and SPI(SPEI) are higher for semiarid locations than for humid ones. This may be due to the fact that SPI and SPEI are normalized indices while PDSI and MedPDSI are influenced by the climate since they result from a soil water balance. Thus, there is not symmetry in the frequencies of negative or positive values of these indices, and this asymmetry is higher for humid climates, which causes their correlation with the normalized SPI and SPEI to decrease. This is influenced by the way PDSI and MedPDSI are calibrated: when calibration focuses on the wettest and driest events, as in this application, the asymmetry is expected to increase; if they are calibrated to satisfy a symetric distribution, the asymmetry decreases and the correlation coefficients may become larger.

Scatter plots of SPI vs. SPEI in a 9-month time scale, MedPDSI vs. SPEI- 9 and PDSI vs. SPEI- 9 are presented in Fig. 2 for Amareleja (semi-arid), Setubal (sub-humid), and Montalegre (humid). The drought severity classification is the same for PDSI and MedPDSI, whose scale is approximately twice that adopted for SPI and SPEI. When comparing SPI and SPEI, it can be observed that scattering decreases from the most dry location (Amareleja) to the wettest one (Montalegre), i.e. the similitude between SPI and SPEI monthly values is higher for humid conditions. This was also verified by Raziei et al. (2011). What is remarkable is that extreme negative values of SPI, indicative of high drought severity, do not have a correspondence in SPEI values, which are hardly lower than -2 (Fig. 2). It was observed, mainly for humid locations like Montalegre (Fig. 2), that the relationship between SPI and SPEI (for 9 and 12 months time scale) is not linear but takes an S shape, thus indicating that the values referring to both very wet and very dry conditions are not identified by values much above 2 or much below -2 . This relates to the fact that the variable of interest in SPEI is P-PET, which behaves differently from $P$, the variable of interest in SPI. In addition, the distribution functions used may influence the results as analysed by Sienz et al. (2011) relative to SPI. The relationships 

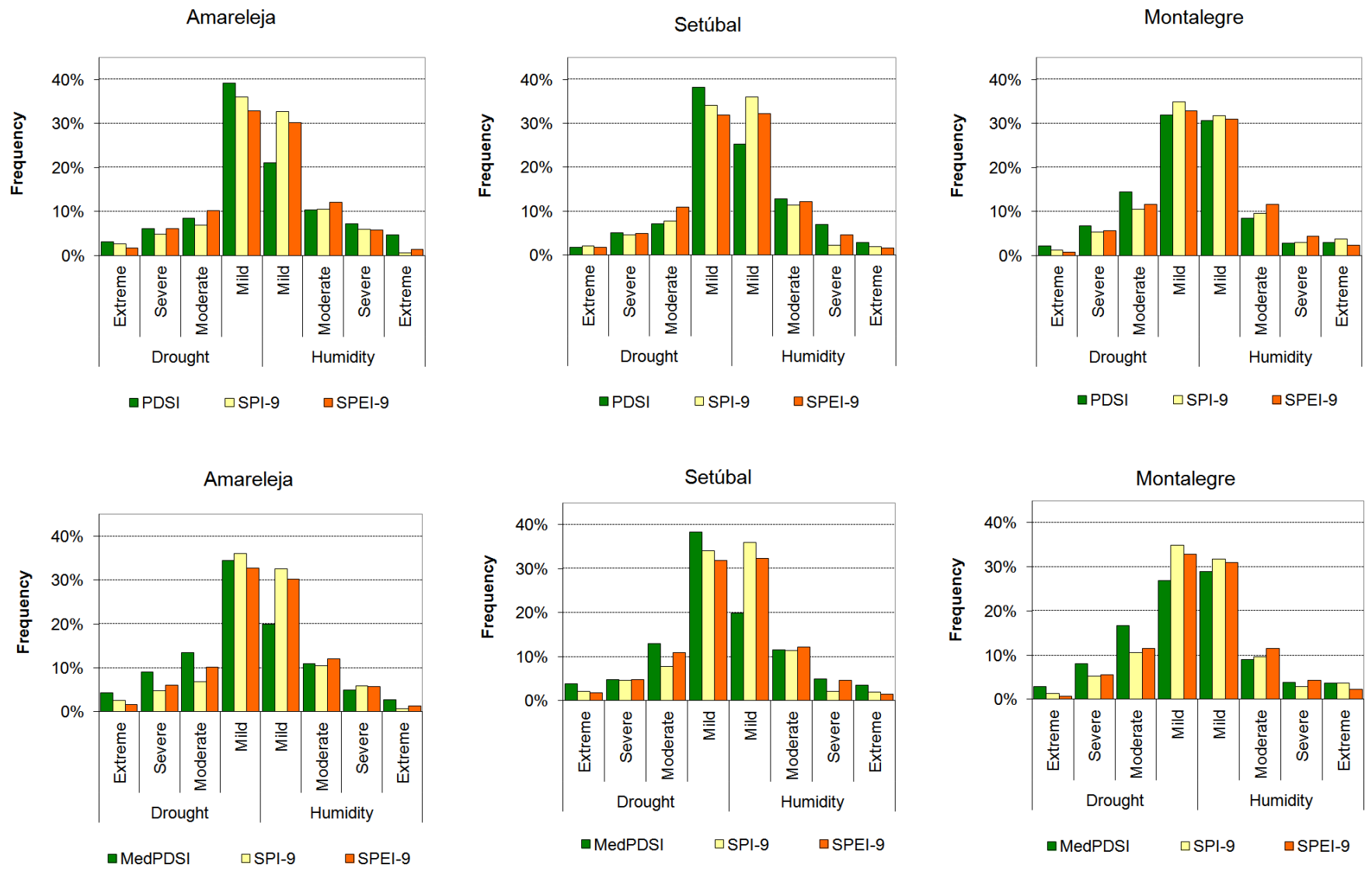

Fig. 4. Frequency of time (\%) in each dry or wet category of MedPDSI, PDSI, SPEI-9, and SPI-9 in Amareleja, Setúbal and Montalegre, 1941-2006.

between MedPDSI or PDSI and SPEI-9 show a large scattering (Fig. 2) due to the backtracking procedure of computation of the drought severity index, mainly for the mild drought or humid states $(-2<$ MedPDSI $<2)$. Despite this dispersion making it more difficult to interpret the scatter plots, it is apparent that there is also less correspondence between the lower and higher values of the PDSI (MedPDSI) and those of SPEI, thus similar to what was observed when comparing SPEI and SPI. The results comparing SPI with PDSI and MedPDSI (not shown herein) show a similar scattering due to the backtracking calculation procedure but do not evidence this behaviour relative to lower and higher values of the indices (Rosa et al., 2010a). The empirical distribution of the drought indices (Fig. 3) for Montalegre (humid) and Amareleja (semi-arid) confirm that the values referring to both very wet and very dry conditions are not identified by SPEI in the same way as they are identified by SPI, PDSI, and MedPDSI. The number of values much above 2 or below -2 in the case of SPI, or much above 4 or below -4 in the case of PDSI and MedPDSI, is clearly larger than those for SPEI above 2 or below -2 . The results for the other stations are similar.
The empirical distributions in Fig. 3 also show differences between the semi-arid Amareleja and the humid Montalegre, with SPI identifying fewer extremely severe droughts at Montalegre and fewer very wet occurrences at Amareleja. Similar results are shown for PDSI and MedPDSI. However, the empirical distribution curves of these indices are different from those of SPI (Fig. 3), particularly for index values between -2 and 2 , due to the referred backtracking effects. Differently, the empirical distribution relative to SPEI9 shows a similar behaviour for Amareleja and Montalegre, i.e. the index does not show sensitivity to climate differences (contrary to what has been observed for Iran, Raziei et al., 2011). This could be considered an advantage as a normalized index, but is not considering that the index may be less reactive under the perspective of supply-demand, which apparently was the reason for its development.

The frequency of time in each dry or wet category, expressed as the percentage of months in a given category, is shown in Fig. 4 for Amareleja, Setúbal, and Montalegre comparing the PDSI and the MedPDSI with both SPEI-9 and SPI9. It is apparent from these results (confirmed for other locations not shown here) that the SPI and SPEI, since they are normalized indices, tend to have about the same frequencies 

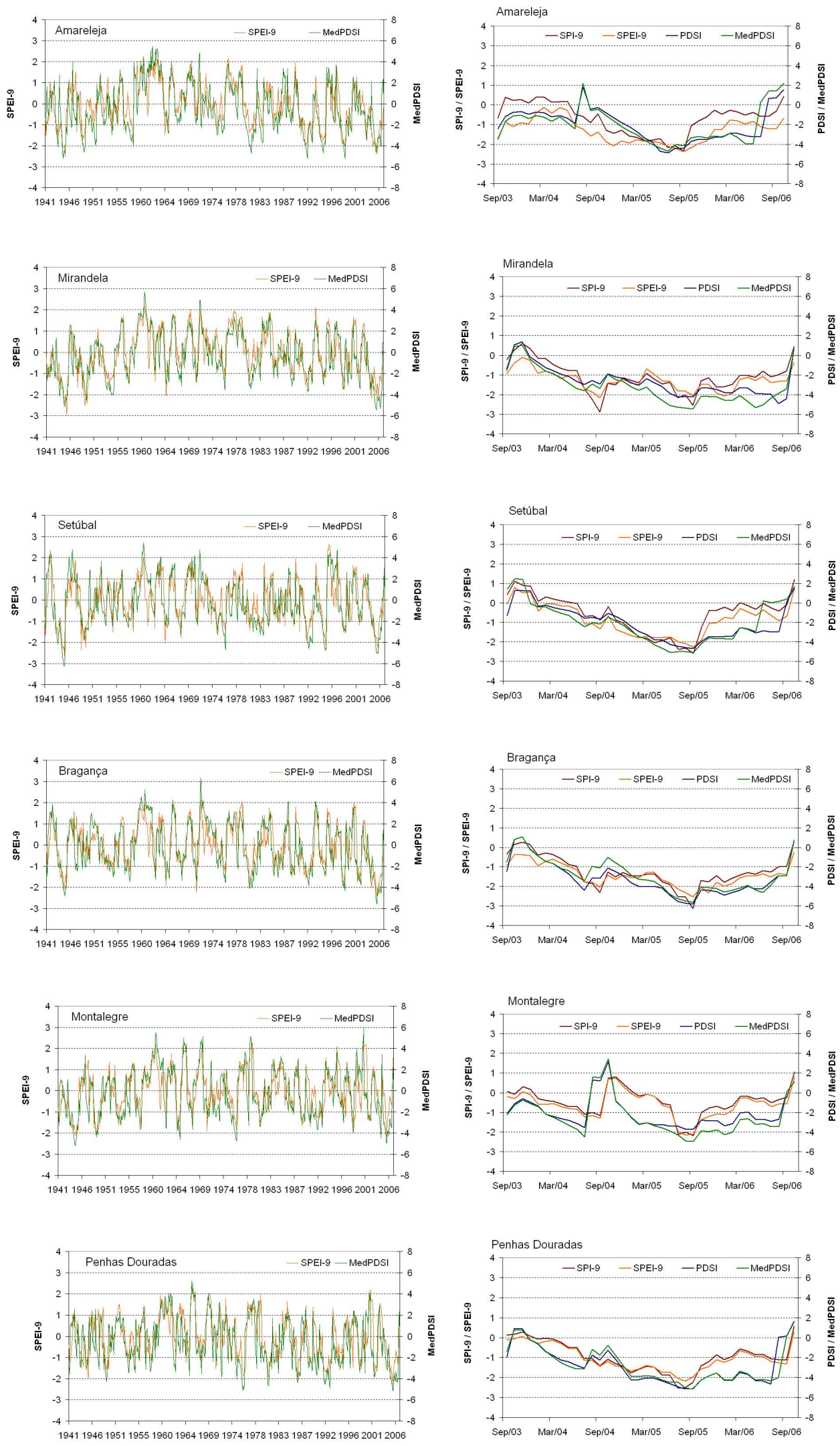

Fig. 5. Time series of SPEI-9 and MedPDSI (1941-2006) and of SPI, SPEI, PDSI, and MedPDSI in selected locations during the severe drought of 2004-2006. 
Table 3. Results of the Mann-Kendall trend test applied to MedPDSI and SPEI.

\begin{tabular}{|c|c|c|c|c|}
\hline & \multicolumn{2}{|l|}{ MedPDSI } & \multicolumn{2}{|l|}{ SPEI } \\
\hline & $\begin{array}{l}\text { Trend test } \\
\text { statistic* }\end{array}$ & $\mathrm{p}$ value & $\begin{array}{r}\text { Trend test } \\
\text { statistic }\end{array}$ & $\mathrm{p}$ value \\
\hline Alcacer do Sal & 0.553 & 0.580 & -0.334 & 0.738 \\
\hline Alvalade & -1.959 & 0.050 & -0.9 & 0.368 \\
\hline Alvega & -2.125 & 0.034 & -0.532 & 0.595 \\
\hline Amareleja & -1.538 & 0.124 & -1.506 & 0.132 \\
\hline Beja & -0.769 & 0.442 & -1.053 & 0.292 \\
\hline Braga & -0.437 & 0.662 & -0.651 & 0.515 \\
\hline Bragança & -2.059 & 0.040 & -1.546 & 0.122 \\
\hline Coimbra/Bencanta & 1.478 & 0.140 & 0.142 & 0.887 \\
\hline Elvas & -1.727 & 0.084 & -2.27 & 0.023 \\
\hline Evora & -2.490 & 0.013 & -2.242 & 0.025 \\
\hline Faro Aeroporto & -0.077 & 0.938 & -0.243 & 0.808 \\
\hline Lisboa (Geofisico) & 1.112 & 0.266 & -0.447 & 0.655 \\
\hline Mirandela & -0.210 & 0.833 & 0.413 & 0.679 \\
\hline Miranda do Douro & -0.869 & 0.385 & -0.277 & 0.781 \\
\hline Montalegre & 0.387 & 0.698 & 0.068 & 0.946 \\
\hline Mora & -3.210 & 0.001 & -2.491 & 0.013 \\
\hline Penhas Douradas & -2.424 & 0.015 & -1.891 & 0.059 \\
\hline Pinhao (Santa Barbara) & 0.935 & 0.350 & 0.419 & 0.675 \\
\hline Portalegre & 0.675 & 0.500 & -1.132 & 0.257 \\
\hline Porto-Serra do Pilar & 2.358 & 0.018 & 0.968 & 0.333 \\
\hline Regua & -0.498 & 0.618 & -2.038 & 0.042 \\
\hline Setubal & -1.378 & 0.168 & -0.674 & 0.501 \\
\hline Vila Real de S. Antonio & -1.527 & 0.127 & -2.587 & 0.010 \\
\hline Viseu & -0.974 & 0.330 & -0.209 & 0.834 \\
\hline
\end{tabular}

$*$ When the p-values $<0.05$, there is a significant trend for droughts' severity to increase if the statistics are negative; otherwise, to decrease.

for dry and wet conditions while the PDSI and MedPDSI have shown a higher frequency in dry categories, mainly for the semiarid locations. However, the behaviour of PDSI and MedPDSI can be influenced by calibration. This may consist of a disadvantage of PDSI (MedPDSI). A greater number of extreme and severe drought/wet months are identified with the PDSI and, mainly, the MedPDSI rather than with the SPEI or SPI. These results reflect the fact that those indices are obtained from monthly soil water balances, thus considering real ET instead of PET, and show the effects of the balance supply-demand better than just computing anomalies in precipitation or P-PET.

The time variation of the indices SPEI-9 and MedPDSI along the period 1941-2006 is presented in Fig. 5 for the six selected locations; on the right are the courses of SPI-9, SPEI-9, PDSI, and MedPDSI just for the drought of 20042006, that struck the entire country quite severely. The comparison between SPEI-9 and MedPDSI shows that generally there are few discrepancies between both indices throughout these $66 \mathrm{yr}$, but lower and higher values are generally identified by MedPDSI and, particularly, drought conditions are identified first by MedPDSI. This indicates that MedPDSI may identify a presumable drought on-set earlier, which is an advantage for prediction of drought class transitions to be used for drought warning. However, the analysis presented here does not allow us to say that true drought onsets were identified first. In case of the drought of 20042006, there is evidence that both indices SPI and SPEI had similar time dynamics, while PDSI and MedPDSI evolved also as a different pair. Differences between pairs are influenced by their different scale categories. However, PDSI and MedPDSI reacted more evidently than SPI and SPEI to the precipitation anomaly because they were computed by a soil water balance. This condition looks particularly interesting when drought monitoring includes agriculture among the objectives of drought warning.

A Mann-Kendall trend analysis was performed for MedPDSI and SPEI-9 (Table 3). Results for MedPDSI show more cases where the test statistics are significant, with 5 cases where droughts tend to aggravate and one case contrary to that trend, Porto, a humid location in the North and close to the Atlantic Ocean. Results for SPEI show 4 cases where droughts tend significantly to aggravate. Only two of those cases are common to both indices, Évora and Mora. Identified but not significant opposed trends were observed for Alcácer, Lisboa, Mirandela, and Portalegre. It is 
worth noting that, as observed for PDSI ( $\mathrm{Hu}$ and Willson, 2000), MedPDSI is sensitive to temperature (and precipitation) trends as identified in Table 1. Moreover, the results obtained agree with trends observed by Sousa et al. (2011).

\section{Conclusions}

Monthly and annual trends in precipitation and mean temperature from 27 weather stations spread over Portugal and the period 1941-2006 were investigated. Significant trends for annual temperature increase were detected in most locations although not exceeding $0.25^{\circ} \mathrm{C}$ per decade; monthly trends were not detected for spring and autumn months and higher increases were observed for August and December. Significant but small trends for precipitation decrease in March were detected in 25 out of 27 stations. Differently, an increase was detected in October in 17 stations and no annual trends were found. It can be concluded that observed changes are small overall.

Various drought indices were analysed focusing possible trends on droughts' occurrence or severity: SPI, using precipitation only, SPEI, using P-ET, and PDSI and MedPDSI that adopt a soil water balance to detect anomalies in the supply-demand balance. A comparison was performed among semi-arid, sub-humid, and humid locations. Correlations between pairs of indices have shown that MedPDSI and PDSI correlate well, as well as SPI and SPEI; the former show good correlations with SPI and SPEI at a 9-month time scale. Analysing the frequency of time in dry or wet categories and the time evolution of drought indices, results show that the MedPDSI and the PDSI identify severe and extreme droughts more frequently than the SPI or SPEI. However, because they are not normalised indices, PDSI and MedPDSI are shown to be negatively biased; this fact relates with their calibration using data from extreme dry and wet events and not searching for a probabilistic balance between dry and wet events.

The SPEI identifies fewer extreme dry and wet values than the other indices. Drought on-set is presumably identified earlier with the PDSI and, mainly, with the MedPDSI. A trend test applied to both the MedPDSI and SPEI data has shown coherent results when comparing both indices. It is worth noting that MedPDSI has been shown to be sensitive to changes in temperature and precipitation that occurred during the last $66 \mathrm{yr}$. Despite MedPDSI requiring further statistical tests and a deeper analysis on alternative calibration procedures (e.g. self calibration), the results allow hypothesizing that PDSI and MedPDSI are likely to identify better the supply-demand dynamics and that they may be of great interest for drought warning applications, aiming namely at agriculture.
Acknowledgements. Data relative to weather stations were provided by the Institute of Meteorology, Lisbon.

Edited by: J. A. Santos

Reviewed by: two anonymous referees

\section{References}

Allen, R. G., Pereira, L. S., Raes, D., and Smith, M.: Crop Evapotranspiration, Guidelines for Computing Crop Water Requirements, Irrigation and Drainage Paper 56, FAO, Rome, 300 pp., 1998.

Alley, W. M.: The Palmer Drought Severity Index: limitations and assumptions, J. Clim. Appl. Meteor., 23, 1100-1109, 1984.

Arora, V. K.: The use of the aridity index to assess climate change effect on annual runoff, J. Hydrol., 265, 164-177, 2002.

Chambers, J. M., Cleveland, W. S., Kleiner B., and Tukey, P. A.: Graphical Methods for Data Analysis, Chapman and Hall, New York, 1983.

de Lima, M. I. P., Carvalho, S. C. P., de Lima, J. L. M. P., and Coelho, M. F. E. S.: Trends in precipitation: analysis of long annual and monthly time series from mainland Portugal, Adv. Geosci., 25, 155-160, doi:10.5194/adgeo-25-155-2010, 2010.

Dracup, J. A., Lee, K. S., and Paulson, E. D.: On the definition of droughts, Water Resour. Res., 16, 297-302, 1980.

Draper, N. R. and Smith, H.: Applied Regression Analysis, John Wiley \& Sons Inc., 1998.

Grigg, N. S. and Vlachos, E. C. (Eds.): Drought Water Management, Colorado State University, Fort Collins, 1990

Guttman, N. B.: Comparing the Palmer drought index and the standardised precipitation index, J. Am. Water Res. Assoc., 34, 113 $121,1997$.

Hamed, K. H. and Rao, R. A.: A modified Mann Kendall test for autocorrelated data, J. Hydrol. 204, 182-196, 1998.

Heddinghaus, T. R. and Sabol, P.: A Review of the Palmer Drought Severity Index and where do we go from here?, in: Proceedings of the 7th Conference on Applied Climatology, American Meteorological Society, 242-246, 1991.

Heim, R. R.: A review of twentieth-century drought indices used in the United States, Bull. Am. Meteor. Soc., 83, 1149-1165, 2002.

Helsel, D. R. and Hirsch, R. M.: Statistical Methods in Water Resources, Elsevier, Amsterdam, 1992.

Hirsch, R. M.: A comparison of four streamflow record extension techniques. Water Resour. Res., 18, 1081-1088, 1982.

Hu, Q. and Willson, G. D.: Effects of temperature anomalies on the Palmer Drought Severity Index in the Central United States, Int. J. Climatol., 20, 1899-1911, 2000.

Huth, R. and Pokorná, L.: Parametric versus non-parametric estimates of climatic trends, Theor. Appl. Climatol., 77, 107-112, 2004.

Karl, T. R.: The sensitivity of the Palmer Drought Severity Index and Palmer's Z-Index to their calibration coefficients including potential evapotranspiration, J. Clim. Appl. Meteor., 25, 77-86, 1986.

Keyantash, J. and Dracup, J. A.: The quantification of drought: an evaluation of drought indices, B. Am. Meteor. Soc., 83, 11671180, 2002.

Liu, Y., Teixeira, J. L., Zhang, H. J., and Pereira, L. S.: Model validation and crop coefficients for irrigation scheduling in the 
North China Plain, Agr. Water Manage., 36, 233-246, 1998.

McKee, T. B., Doesken, N. J., and Kleist, J.: The relationship of drought frequency and duration to time scales, in: 8th Conference on Applied Climatology, 17-22 January, Anaheim, CA, 179-184, 1993.

McKee, T. B., Doesken, N. J., and Kleist, J.: Drought monitoring with multiple time scales, in: 9th Conference on Applied Climatology, Am. Meteor. Soc., Boston, 233-236, 1995.

Mishra, A. K. and Singh, V. P.: A review of drought concepts, J. Hydrol., 391, 202-216, 2010.

Moreira, E. E., Coelho, C. A., Paulo, A. A., Pereira, L. S., and Mexia, J. T.: SPI-based drought category prediction using loglinear models, J. Hydrol., 354, 116-130, 2008.

Ntale, H. K. and Gan, T. Y.: Drought indices and their application to east Africa, Int. J. Climatol., 23, 1335-1357, 2003.

Palmer, W. C.: Meteorological Drought, Research Paper No. 45, US Department of Commerce Weather Bureau, Washington, DC, 1965.

Paulo, A. A. and Pereira, L. S.: Drought concepts and characterization. Comparing drought indices, Water Int., 31, 37-49, 2006.

Paulo, A. A. and Pereira, L. S.: Stochastic prediction of drought class transitions, Water Resour. Manage., 22, 1277-1296, 2008.

Pereira, L. S. and Rosa, R. D.: O índice de Palmer modificado para clima Mediterrânico (MedPDSI), 1. Desenvolvimento, in: Gestão do Risco em Secas, Métodos, Tecnologias e Desafios, edited by: Pereira, L. S., Mexia, J. T., and Pires, C. A. L., Edições Colibri e CEER, Lisboa, 15-34, 2010.

Pereira, L. S., Rosa, R. D., and Paulo, A. A.: Testing a Modification of the Palmer Drought Severity Index for Mediterranean Environments, in: Methods and Tools for Drought Analysis and Management, edited by: Rossi, G., Vega, T., and Bonaccorso, B., Springer, Dordrecht, 149-167, 2007.

Pereira, L. S., Cordery, I., and Iacovides, I.: Coping with Water Scarcity. Addressing the Challenges, Springer, Dordrecht, 382 pp., 2009.

Raziei, T., Bordi, I., Pereira, L. S., and Sutera, A.: Detecting impacts of a changing climate on drought characteristics in Iran, in: Water Engineering and Management in a Changing Environment, edited by: Cancellieri, A. and Rossi, G., (VIth EWRA Int. Symp., Catania, Italy), Quaderni CSEI Catania, III Serie, Vol. 6, CD-Rom, 2011.

Rosa, R. D., Pereira, L. S., and Paulo, A. A.: O MedPDSI, uma modificação do índice de Palmer para clima mediterrânico, 2, Aplicação ao país, in: Gestão do Risco em Secas, edited by: Pereira, L. S., Mexia, J. T., and Pires, C. A. L., Métodos, Tecnologias e Desafios, Edições Colibri e CEER, Lisboa, 35-58, 2010a.
Rosa, R. D., Paulo, A. A., Matias, P. G., Espírito Santo, M. F., and Pires, V. C.: Tratamento da qualidade das séries de dados climáticos quanto a homogeneidade, aleatoriedade e tendência e completagem de séries de dados, in: Gestão do Risco em Secas, edited by: Pereira, L. S., Mexia, J. T., and Pires, C. A. L., Métodos, Tecnologias e Desafios, Edições Colibri, CEER, 119139, $2010 b$.

Sen, P. K.: Estimates of the regression coefficient based on Kendall's tau, J. Am. Stat. Assoc., 63, 1379-1389, 1968.

Sienz, F., Bothe, O., and Fraedrich, K.: Monitoring and quantifying future climate projections of dryness and wetness extremes: SPI bias, Hydrol. Earth Syst. Sci. Discuss., 8, 10635-10677, doi:10.5194/hessd-8-10635-2011, 2011.

Sousa, P. M., Trigo, R. M., Aizpurua, P., Nieto, R., Gimeno, L., and Garcia-Herrera, R.: Trends and extremes of drought indices throughout the 20th century in the Mediterranean, Nat. Hazards Earth Syst. Sci., 11, 33-51, doi:10.5194/nhess-11-33-2011, 2011.

Tate, E. L. and Gustard, A.: Drought definition: a hydrological perspective, in: Drought and Drought Mitigation in Europe, edited by: Vogt, J. J. and Somma F., Kluwer, Dordrecht, 23-48, 2000.

Thornthwaite, C. W.: An approach toward a rational classification of climate, Geogr. Rev., 38, 55-94, 1948.

Tsakiris, G., Pangalou, D., and Vangelis, H.: Regional drought assessment based on the reconnaissance drought index (RDI), Water Resour. Manage., 21, 821-833, 2007.

United Nations Environment Programme (UNEP): World Atlas of Desertification, 1992.

Vicente-Serrano, S. M., Begueria, S., and López-Moreno, J. I.: A multiscalar drought index sensitive to global warming: The Standardized Precipitation Evapotranspiration Index, J. Climate, 23, 1696-1718, 2010a.

Vicente-Serrano, S. M., Lasanta, T., and Gracia, C.: Aridification determines changes in forest growth in Pinus halepensis forests under semiarid Mediterranean climate conditions, Agr. Forest Meteorol., 150, 614-628, 2010b.

Vogel, R. M. and Stedinger, J. R.: Minimum variance streamflow record augmentation procedures, Water Resour. Res., 21, 715723, 1985.

Yevjevich, V., Cunha, L. V., and Vlachos, E. (Eds.): Coping with Droughts, Water Resources Publications, Littleton, Colorado, 1983,

Wilhite, D. A.: Drought Assessment, Management, and Planning: Theory and Case Studies, Natural Resource Management and Policy Series, Vol. 2, Kluwer, 1993.

Wilhite, D. A. and Glantz, M. H.: Understanding the drought phenomenon: the role of definitions, in: Planning for Drought, edited by: Wilhite, D. A., Easterling, W. E., and Wood, D. A., Vestview Press, Boulder, CO, 11-27, 1987. 